\title{
ЭКСПЛИКАЦИЯ КАТЕГОРИИ ПРЕДЕЛ В СОВРЕМЕННОЙ ФИЛОСОФИИ
}

Аннотация. В статье преследуется цель расширить методологическую базу социально-философских исследований пределов развития общества. Обозначены проблемные вопросы, связанные с оформлением социально-философского дискурса о пределах развития общества.

Ключевъе слова: философия, предел, изменения, развитие, мера, конверсия, самоорганизация, процесс, дискурс, категория.

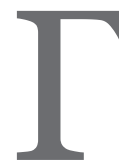

лобальный системный кризис, с которым столкнулось человечество в новом тысячелетии, заставил задуматься об особенностях социальных изменений в современном мире. Все более очевидным становится тот факт, что историческое движение достигло некоего предела, на границе которого развернулись бурные драматические события. Пристальному вниманию исследователей предстала специфическая область реальности: кризисные состояния, пограничные зоны взаимодействия различных систем, предельная неустойчивость и относительность бытия. Сегодня человечество все больше теряет ориентацию в мире, отрывается от онтологических начал своего существования. Поэтому проблематика социальных изменений общественной жизни остро стоит перед сегодняшними исследователями. Требуются концепции, позволяющие ориентироваться в постоянно меняющемся обществе, в условиях становления новых правил взаимодействия отдельных элементов и подсистем внутри видоизменяющейся социальной системы. В связи с этим появились совершенно новые философские проблемы, работа над решением которых заставляет по-иному взглянуть на классические проблемы человека и общества.

Со вступлением человеческой истории в этап исторического перехода, связанного с социальноэкономическими и духовными преобразованиями, переоценкой старых ценностей и созданием новых ценностей, связано включение феномена предела в категориальную систему философии. Осознание феномена предела как реальности и его влияния на социум многозначно. Ситуация настоятельно требует научной, а точнее - философской рефлексии, этой действительности и ее достаточно широких преломлений. Предел понимается нами как общее свойство универсума, которое является объективным атрибутом всех сфер природы, социума и человека.

Необходимость постановки проблемы предела/пределов связана с тем, что на протяжении последних полутора веков из всех фундаментальных и прикладных отраслей знания приходили «сигналы», свидетельствующие, что к числу важных, хотя и нетрадиционных для философского дискурса универсальных закономерностей, относится закономерность, выражающая действие предела универсального элемента эволюционного механизма изменения, действующего особым образом в рамках каждой конкретной области действительности. На сегодняшний день принципиально невозможно осуществить на теоретическом уровне анализ появляющихся новых проблем, если нет ясности и четкости определения научных понятий. Известно, что категории являются важнейшими элементами консолидации теоретического дискурса, они выступают в виде «сгустков» познания, его концентраций. С точки зрения философии, категории являются формой закрепления полученных знаний и являются инструментом дальнейшего изучения мира.

Довольно сложной задачей оказывается задача формулировки категории предел. Ответить на вопрос: что такое предел? Поиски конструктивного ответа на данный вопрос - цель настоящей работы.

Возможно несколько путей поиска ответов на обозначенный выше вопрос. 


\section{Философия и культура 8(68) • 2013}

Первый и наиболее заманчивый - рассмотреть все возможные случаи предела в каждой из фундаментальных наук о природе, обществе и познании. Однако этот путь, наряду с несомненными достоинствами (анализ реальных пределов), содержит в себе и явные недостатки. Частные подходы, принципиально незавершенные и неполные по своей сути, не дают ответа на вопрос о сущности предела и поэтому не являются всеобщими определениями даже во всей своей совокупности.

Второй путь рассмотрения предела. Можно сделать обобщение частных случаев исходя из анализов конкретно-научных типов пределов. Но и такой подход будет недостаточно полным и сущностным. Он будет содержать в себе ограниченности неполной индукции. Это будет один из возможных вариантов ответа на вопрос, в зависимости от того, какой из типов предела примет исследователь за основной и базисный для обобщающих выводов.

Третий и наиболее перспективный вариант исходить из общей теории развития, частным случаем которого является предел. Однако в этом случае мы не сможем покинуть поле дискуссий, так как понимание развития, а вместе с ним и предела было исторически различным, остается таковым и сейчас и будет неоднозначным в будущем. Это значит, что дать всеобъемлющее определение категорий развития и предела, абсолютно истинное толкование их в принципе невозможно, как, в прочем, и любой другой философской категории. Но можно отразить суть вопроса исходя из общего уровня развития научного и философского знаний. Это должно быть синтетическое суждение, основанное на единстве индуктивного и дедуктивного методов анализа, обобщении исторического опыта и интуитивном озарении мысли.

Категория предел исключительно многообразна и многослойна, непосредственно это раскрывается при попытке обнаружить ее определенное содержание как фиксированного слова в языке философии, так как употребление ее оказывается настолько широким и разноплановым, что представляется затруднительным очертить четкую сферу ее применения. О пределе пишут как о крайней черте чего-либо, как о норме или запрете, как о законе, пределы прилагают к пространственной и временной характеристике материального мира, к математическим и физическим объектам, к человеческому бытию вообще, к естественноприродным процессам и т.д. Неоднозначность, но и универсальность данной категории можно обна- ружить в языковых интерпретациях, традициях. Размышляя о категории предел неизбежным становится ситуация тавтологии (описанная М. Хайдеггером), так как сам язык пронизан пределами, предельными являются и человеческая природа и разум и чувства.

Неоднозначны и трактовки определения предела в зависимости от типа носителя, продуцента опыта, от выбранного круга общественной проблематики, от внешнего или внутреннего плана рассмотрения. Предел и все, что с ним связано, находит воплощение в различных теоретических построениях, зависящих от особых «культурноисторических априори», важнейшим из которых является язык. Люди, живут не только в материальном и социальном мире, а «в значительной степени они все находятся во власти того конкретного языка, который стал средством выражения в данном обществе» ${ }^{1}$. Проблема определения категорий и понятий выражена в известной гипотезе «Сепира-Уорфа» о лингвистической относительности: «Мы расчленяем мир, организуем его в понятия и распределяем значения так, а не иначе в основном потому, что мы - участники соглашения, предписывающего подобную систематизацию <...> Определить явление, вещь, предмет, отношение и тому подобное, исходя из природы, невозможно; их определение всегда подразумевает обращение к категориям того или иного конкретного языка» ${ }^{2}$. Таким образом, «мышление всегда движется в колее, пролагаемой языком. Языком заданы как возможности мышления, так и его границы. Но о том же самом говорит и опыт интерпретации, которая в свою очередь, имеет языковой характер. Когда, например, мы не понимаем некоторый текст и отдельное слово озадачивает нас своей многозначностью, предлагая разные возможности своего истолкования, мы, бесспорно, имеем дело с препятствием на пути языкового осуществления понимания» ${ }^{3}$. Именно при попытке определения сущности предела бросается в глаза его противоречивость и парадоксальность. Первый парадокс возникает уже в попытке семантического определения предела. Так как определить предел - значит ограничить его, положить ему предел/границу,

\footnotetext{
1 Сепир Э. Избранные труды по языкознанию и культурологии. М.: Прогресс, 1993. С. 261.

2 Уорф Б.Л. Наука и языковедение // Новое в лингвистике. Вып. 1. М.: Иностранная литература, 1960. С. 175-177.

3 Гадамер Г.-Г. Философия и герменевтика // Гадамер Г.-Г. Актуальность прекрасного. М.: Искусство, 1991. С. 13.
} 


\section{Социальная динамика}

указав на родовую и видовую принадлежность. Таким образом, рефлексия по поводу сущности предела попадает в собственный герменевтический круг. Однако круг этот имеет онтологический характер - от него невозможно, да и не нужно освобождаться. По мнению Гадамера мы не можем преодолеть исторической обусловленности нашего понимания. Он говорит о «ситуационной укорененности» понимающего субъекта. Причем видит в этой укорененности положительное начало для исторического понимания.

В современном научном тезаурусе употребление слова предел - явление обыденное. Категорией предела оперируют практически все, от обыденного языка, до сложных математических и философских теорий. В самом общем смысле его смысл понятен всем, однако в специальном философском понимании нигде не проясняется. Парадоксально приобретя право быть и восприниматься научным сообществом в качестве специального термина, предел не имеет четкой дефиниции. Чаще всего предел используется, вопервых, в своем буквальном значении как граница, рубеж, допустимая норма, и, во-вторых, как составная часть словосочетаний, в которых он, уточняет временные или пространственные рамки (предел эпох, предел терпения, за пределом).

Значительная часть терминологической неоднозначности вокруг категории предел в философии объясняется тем, что социальный конструкт, описываемый данным термином, постоянно изменяется и развивается. Разночтения в дефинициях, по мнению автора, являются естественным следствием многослойности, многосторонности, необычайной многогранности пределов как природного, так и социального явления. Определение предметной сущности предела оказывается практически невозможным, так как он является скорее условностью, чистым «опосредствованием» (Гегель). Поэтому лишь рефлексия опосредствует сущность предела, средствами понятийного аппарата. Сущность предела возможна только в замкнутом размышлении о нем самом.

Занявшись философским терминотворчеством, необходимо отметить, что введение, или вернее возвращение, в философскую науку категории предел осуществляется при помощи приема, известного как прием семантической конверсии, то есть перевода слов общеупотребительного языка в разряд научных терминов. Поэтому, в данном случае, считаем уместным, начать формирование определения категории предел с изучения его трактовки в общеизвестном словаре русского языка.

В Словаре русского языка, 1983 года даются следующие значения слова предел:

1. край, конечная часть чего-либо. Переносное: конец, окончание, завершение чего-либо.

2. мн.ч. пределы. Естественная граница или условная черта, являющаяся границей какой-либо территории; рубеж. Местность, пространство, заключенные в какие-либо границы. Край, страна. Промежуток времени ограниченный какими-либо сроками (обычно в сочетании в пределах).

3. Мера, граница чего-либо; рамки. Высшая степень чего-либо.

4. Математическое. Постоянная величина, к которой приближается переменная величина, зависящая от другой переменной величины, при определенном изменении последней ${ }^{4}$.

Первоначально в русском языке слово предел состояло из старославянской приставки пре (значение предельной степени действия, превосходящего какую-либо меру, или высшей степени качества) и корня дел/дело. Слово дело может иметь значение: работа, занятие; нечто важное, нужное; факт; положение вещей. Таким образом, в русском языке предел - это начало и конец какого-либо дела, события; преодоление сложившегося положения вещей; самый важный момент. С течением времени произошло опрощение слова предел, когда аффиксы теряют свой смысл в составе слова, Происходит их слияние с корнем, и слово, бывшее ранее производным, осознаётся как простое, ни от чего не образованное. При этом чтобы устранить многозначность в понимании слова предел, в русском языке, было заимствовано из английского языка слово финиш (заключительная часть спортивных соревнований), из итальянского - финал (конец какого-либо события, дела, явления), из греческого - эпилог (заключительная часть литературного произведения).

При работе с категорией предел необходимо учитывать:

- отсутствие достаточно развитой теории, которую можно было бы использовать целиком, включая категорию предел, как одно из обоснованных в ней понятий;

- необходимость, тем не менее, опираться на некоторые уже существующие теории. Это

\footnotetext{
${ }^{4}$ Словарь русского языка: в 6 т. Т. 3 (п-р). М.: Русский язык,
} 1983. С. $344-345$. 


\section{Философия и культура 8(68) • 2013}

означает оперирование существующими в них категориями предел, предельность, и использование, прежде всего, чисто логических средств в тех случаях, когда эти категории нуждаются в уточнении применительно к социально-философскому дискурсу.

Таким образом, работа над категорией предел включает в себя две взаимосвязанные задачи:

- прояснение статуса категории в рамках социально-философских наук;

- применение и модификация данной категории в ходе ее теоретического осмысления.

Для полноты исследования, раскрытия сущности категории предел, ликвидации разрыва между его использованием в конкретной науке и философии, необходимо его связать с более общими философскими категориями. Этот процесс носит всеобщий характер, известный как метод дедукции, когда из общих категорий выводят более частные, то есть идет процесс актуализации категорий, в результате чего они начинают отражать не только всеобщее, но и общее, признаки, черты признаков и явлений. При этом, исследование предела должно быть направлено на понимание его как свойства, присущего атрибутам материи, и, в первую очередь, развитию, понимаемому как всякое изменение. Сколько бы мир не менялся, пределы все равно будут вплетены в ткань мира. Поэтому следует рассмотреть эту категорию применительно к развитию (изменению) вообще, а так же к пространственно-временным событиям в природе и обществе. Категория «развитие» выражает глубинную сущность объективного мира (природы). Однако она «выражает не просто изменение вообще, то есть движение (в онтологическом или гносеологическом аспектах), и не просто факт обновления, возникновения новых формообразований, то есть становление, а применительно к материи вообще - «способ её осуществления как деятельной субстанции, творящей свои конкретные формы по объективным законам» 5. Развитие именно та категория, на основании которой только и возможно построить целостную модель объективного мира, так как «развитие это реализация потенциальных возможностей как последовательная связь состояний системы в процессе ее эволюции» ${ }^{6}$. Развитие, как фило-

\footnotetext{
${ }^{5}$ Агеев В.В. Введение в психологию человеческой уникальности. Томск: Пеленг, 2002. С. 428.

${ }^{6}$ Осипов В.Е. Категория развития в системе диалектики // Культура. Наука. Образование. 2008. № 4. С. 20.
}

софская категория предполагает процесс любого рода изменений разнообразных форм материи. Для него характерен ряд наиболее существенных позиций. Это потенциальность, поступательность, поливариантность.

Развитие, является наиболее общей искомой родовой категорией для категории предел и выступает для нее в своем более конкретном выражении - изменении. Изменение означает смену структур и функций систем различного уровня развития, структурной организации и степени сложности органического строения. Изменения это различия между тем, что представляла система в прошлом, и тем, что стало с ней через определенный период времени. При этом именно изменчивость позволяет появляться различным вариантам «полю возможностей», из которого потом возникает многообразие форм материи. Вместе с тем изменчивость служит так же и причиной разрушения данных форм.

Всякое изменение постоянно связано и не может существовать без своей противоположности относительной устойчивости или сохранности равновесия материи. При этом пределы изменений всегда ограничиваются противостоящей устойчивостью. Понятие «устойчивость» общефилософское, используется в различных областях знаний, отражает отношение человека с природой и присуще всем природным образованиям и социальным формированиям. При этом предел, как форма изменения, обладает имманентными качественными характеристиками. Он означает процесс смены качественной определенности любой данной системы, взятой как целое в единстве своих субстанциальных оснований и функциональной деятельности. В этом случае категория предел синтезирует в своем содержании единство изменения структуры и функций в процессе их целостного развития. И, наконец, предел как категория включает не любой процесс изменений, а лишь переходный (от устойчивости к неустойчивости) по отношению к любой конкретной форме материи.

Как известно, изменения могут происходить как постепенное накопление количественных изменений (эволюция), и как быстрые качественные изменения (революция). В тоже время они могут рассматриваться как восходящие изменения (прогресс) и нисходящие (регресс). При этом каждый уровень изменений имеет и свои пределы. Так эволюционные количественные изменения подчиняются простым прави- 


\section{Социальная динамика}

лам, которые отметил Пер Бак в своей теории «самоорганизующихся явлений». Суть данных наблюдений состоит в том, что количественные изменения всегда имеют определенный предел, при этом данный предел имеет определенную степень на временной и размерной шкале, причем всегда одну и ту же степень. «К сожалению, управлять этим процессом мы не можем. В наших силах лишь проведение мониторинга событий и принятие правильных мер, когда что-то происходит» 7 .

Предел, понимаемый как категория изменения, сопряженный как с количественными, так и с качественными изменениями, всегда соотносится с философской категорией мера, без которой невозможно понимание развития (изменения). Именно мера отражает граничные условия, в пределах которой может существовать баланс между качеством и количеством в пределах старой формы. Процесс интеграции количества в качество может привести к выходу за пределы ограничений меры. Это приводит к формированию качественно новой формы и новых пределов. При этом выход за пределы может быть не только на основе интеграции качества и количества, но и характеризовать обратный процесс - дифференциацию качества и количества. В данном случае мы будем иметь дело с процессами деградации качества. В результате которых при выходе за пределы меры, последнее переходит на низший уровень.

Как философская категория мера, традиционно используется в контексте отображения взаимосвязи и взаимозависимости количественных и качественных изменений. Об универсальном значении термина меры свидетельствует факт использования его и его аналогов для характеристики, описания всех жизненно важных сторон социокультурного бытия древних народов. Здесь мера и инструмент практических процедур счета, измерения, взвешивания; мера - как соразмерность количественных и качественных характеристик явлений окружающего бытия; мера - как нравственная норма; мера - как эстетический принцип; мера - как установление отношения; мера - как абсолют, высший закон, универсальная норма. Мера в древней философии досократиков истолкована ими как серединная грань, сердцевина крайних значений явления, порочных крайностей поведения; устранение излишка; целостность; отграниченность; харак- теристика достояния богов. Отсутствие меры трактуется как бездна, хаос, угроза, несчастье, порок, беззаконие, безумие, иррациональность. Платон вывел понятие меры из диалектического взаимодействия предела и беспредельного. Именно он одним из первых попытался выявить меру (как гармонию).

Процесс, развивающийся в рамках меры, функционирует неопределенно долго, пока внешние силы не выведут его из стабильного состояния. Нарушение меры ведет к изменению. Еще Аристотель обратил внимание на то, что оптимальность противостоит экстремальности, и чтобы найти эту середину, надо знать крайности, то есть пределы. Например, культ будущего (утопизм) или настоящего (прагматизм), розовый оптимизм или черный пессимизм. Во всем должна присутствовать мера. Таким образом, мера выступает как момент устойчивого развития, а предел, как момент неустойчивости/нестабильности.

Изменения лежат в основе функционирования всех механизмов нашего мира. При этом стабильность, нестабильность, изменения, и предел проявляются в контексте необходимости, то есть законов, управляющих движением материи и развитием ее организационных форм. Однако многие из причин, порождающих данные явления до сих пор неясны. Возможно выявить ряд причин, по которым предел не заметен для глаз исследователя, а тем более не вооруженным научным аппаратом человека. Дело в том, что чем ближе предел, тем он абстрактнее. Человек может находиться в пределе и не видеть его. Найти предел жизни так же нелегко, как и предел человеческой выносливости. Переход конечности в бесконечность так же непостижим, как и переход бесконечности в конечность. При этом предел разделяет мир, но в то же время и объединяет его, служа основой связи различных сторон и их разнообразных отношений. Категория предел отражает характер завершения реальных процессов изменения, их сущность и включенность в более широкие связи и отношения. Более полный анализ категории предела предполагает выяснение его связи с законами и различными категориями диалектики, такими, например, как становление, движение, прогресс и регресс; исследование конкретных форм развития природных, социальных систем и сферы духовной деятельности человека.

7 Янсен Ф. Эпоха инноваций. М.: ИНФРА-М, 2002. С. 62. 


\section{Философия и культура 8(68) • 2013}

\section{Список литературъ:}

1. Агеев В.В. Введение в психологию человеческой уникальности. Томск: Пеленг, 2002. 498 с.

2. Гадамер Г.-Г. Философия и герменевтика // Гадамер Г.-Г. Актуальность прекрасного. М.: Искусство, 1991. $367 \mathrm{c}$.

3. Осипов В.Е. Категория развития в системе диалектики // Культура. Наука. Образование. 2008. № 4. C. 5-28.

4. Сепир Э. Избранные труды по языкознанию и культурологи. М.: Прогресс, 1993. 656 с.

5. Словарь русского языка в 6 томах. Т. 3 (п-р). М.: Русский язык, 1983. 750 с.

6. Уорф Б.Л. Наука и языковедение // Новое в лингвистике. Вып. 1. М.: Иностранная литература, 1960.

7. Янсен Ф. Эпоха инноваций. М.: ИНФРА-М, 2002. 308 с.

\section{References (transliteration):}

1. Ageev V.V. Vvedenie v psihologiyu chelovecheskoy unikal'nosti. Tomsk: Peleng, 2002. 498 c.

2. Gadamer G.-G. Filosofiya i germenevtika // Gadamer G.-G. Aktual'nost' prekrasnogo. M.: Iskusstvo, 1991. $367 \mathrm{~s}$.

3. Osipov V.E. Kategoriya razvitiya v sisteme dialektiki // Kul'tura. Nauka. Obrazovanie. 2008. № 4. S. 5-28.

4. Sepir E. Izbrannye trudy po yazykoznaniyu i kul'turologi. M.: Progress, 1993. $656 \mathrm{s.}$

5. Slovar russkogo yazyka v 6 tomah. T. 3 (p-r). M.: Russkiy yazyk, 1983. $750 \mathrm{~s}$.

6. Uorf B.L. Nauka i yazykovedenie // Novoe v lingvistike. Vyp. 1. M.: Inostrannaya literatura, 1960.

7. Yansen F. Epoha innovaciy. M.: INFRA-M, 2002. 308 s. 